\title{
Determination of Triethylamine, Pyridine and Dimethyl Formamide Content in Telmisartan by Headspace Gas Chromatography Using Flame Ionization Detector
}

J. GOPALAKRISHNAN*AND S. ASHA DEVI ${ }^{1}$

Piramal Enterprises Limited, Analytical Development Laboratory, 1, Nirlon complex, Off Western expressway, Goregaon (E), Mumbai-400 101, ${ }^{1}$ School of Biosciences and Technology, VIT University, Vellore-632 014 , India

Gopalakrishnan and Asha Devi: Determination of triethylamine, pyridine and dimethyl formamide in telmisartan 
Triethylamine, pyridine and dimethyl formamide are used as solvents in the synthesis of telmisartan. A simple, accurate and precise analytical method for determination of triethylamine, pyridine and dimethyl formamide in telmisartan was developed on headspace gas chromatography. The sample was dissolved in $\mathrm{N}$-methyl pyrrolidone. Headspace vials of standard size and volume of $20 \mathrm{ml}$ capacity were used for the study. The vials were incubated at $100^{\circ}$, for $20 \mathrm{~min}$. Injection volume of headspace in to the gas chromatograph was $1 \mathrm{ml}$. The syringe temperature was maintained at $110^{\circ}$. The injector and detector temperature were $200^{\circ}$ and $250^{\circ}$, respectively. Nitrogen gas was used as carrier gas with flow rate of $1 \mathrm{ml} / \mathrm{min}$. Split ratio was 1:10. DB624 column with $30 \mathrm{~m} \times 0.32 \mathrm{~mm}$ i.d., $1.8 \mu \mathrm{m}$ film thickness was used. Column oven temperature was maintained at $40^{\circ}$ for $15 \mathrm{~min}$, followed by an increase up to $240^{\circ}$ with the rate of $30^{\circ} / \mathrm{min}$. The final temperature of the column with $240^{\circ}$ was maintained for $5 \mathrm{~min}$. This analytical method was validated with respect to precision, linearity, recovery, limit of detection and limit of quantification.

Key words: Telmisartan, N-Methyl pyrrolidone, Triethylamine, Pyridine, Dimethyl formamide, Headspace gas chromatography

Organic solvents such as triethylamine, pyridine and dimethyl formamide are commonly used as solvents in synthesis of many pharmaceutical compounds. They should be controlled to a minimum level in the final product and their limits are fixed based on their toxicity according to ICH guidelines for residual solvents. In general, residual solvents are determined by headspace gas chromatographic technique as per Pharmacopoeia. Most of the organic solvents such as acetone, chloroform, benzene, toluene, hexane and dichloromethane are chemically non-reactive in nature during analysis by headspace chromatography. For determination these types of solvents, diluents are selected based on the solubility of the sample and the solvents to be determined.

Solvents like triethylamine and pyridine are basic in nature. Due to their basicity, they can react with solvent medium used for dilution of the sample or with the sample itself. Primary and secondary amines were reported to be analyzed after derivatization technique by either gas chromatography or headspace gas chromatography ${ }^{[1]}$. The experimental concerns during analysis of amines by headspace chromatography were reported and addressed by Kott and Chen ${ }^{[2]}$. Influence of $\mathrm{pH}$ of the diluent in aqueous medium during static headspace analysis of aliphatic amines was reported by Maris et $a l^{[3]}$. Amines were reported to be analyzed at higher $\mathrm{pH}$ after addition of strong aqueous alkali to the sample by headspace gas chromatography ${ }^{[4-7]}$.

Triethylamine, pyridine and dimethyl formamide were reported to be used in the synthesis of telmisartan ${ }^{[8]}$. The specification limit for triethylamine, pyridine and dimethyl formamide is 320, 200 and $880 \mathrm{ppm}$, respectively ${ }^{[9,10]}$. The aim of our study is to develop an accurate and precise analytical method for determination of these solvents in telmisartan. Structure of telmisartan is shown in fig. 1.
Triethylamine, pyridine and dimethyl formamide, were obtained from Merck, India. N-methyl pyrrolidone was obtained from Biosolve. Telmisartan was procured from a pharmaceutical company.

Triethylamine $(3.2 \mu \mathrm{g} / \mathrm{ml})$, pyridine $(20 \mu \mathrm{g} / \mathrm{ml})$ and dimethyl formamide $(88 \mu \mathrm{g} / \mathrm{ml})$ were prepared in $\mathrm{N}$-methyl pyrrolidone. Standard solution $(5.0 \mathrm{ml})$ was used in headspace vials for standard preparation. Sample vials were prepared by transferring sample and $5.0 \mathrm{ml}$ of $\mathrm{N}$-methyl pyrrolidone in to headspace vials. The headspace vials were sealed tightly. For estimation of triethylamine content, the sample size was $50 \mathrm{mg}$ and for estimation of pyridine and dimethyl formamide the sample size was $500 \mathrm{mg}$.

Thermo focus gas chromatography equipped with split/split less injector, column oven, a flame ionization

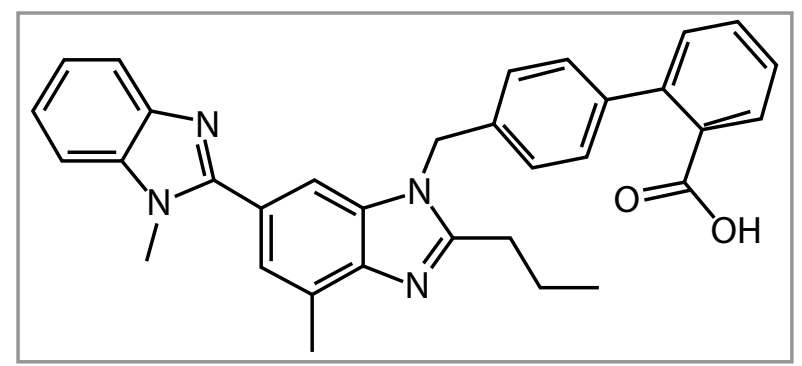

Fig. 1: Structure of telmisartan.

Typical structure of telmisartan is shown. Carboxylic acid group present in the structure is more reactive and interacts with triethylamine.

This is an open access article distributed under terms of the Creative Commons Attribution-NonCommercial-ShareAlike 3.0 License, which allows other the remix, tweak, and build up to the non-commercially, as long as the author is credited and the new creations are licensed under the identical terms.

Accepted 25 May 2016

Revised 15 May 2016

Received 02 Sep 2015

Indian J Pharm Sci 2016;78(3):413-416 
detector, headspace auto sampler (Thermo) was used. The auto sampler was equipped with a glass syringe with $2.5 \mathrm{ml}$ capacity along with temperature controller. Headspace vials of standard size and volume of 20 $\mathrm{ml}$ capacity were used for the study. The vials were incubated at $100^{\circ}$ for $20 \mathrm{~min}$. The syringe temperature was maintained at $110^{\circ}$. DB624 column with 30 $\mathrm{m} \times 0.32 \mathrm{~mm}$ i.d., $1.8 \mu \mathrm{m}$ film thickness was used. The injector and detector temperature were $200^{\circ}$ and $250^{\circ}$, respectively. Column oven temperature was maintained at $40^{\circ}$ for $15 \mathrm{~min}$, followed by an increase up to $240^{\circ}$ with the rate of $30^{\circ} / \mathrm{min}$. The final temperature of the column with $240^{\circ}$ was maintained for 5 min.-

During development stage, trials were made using various non-aqueous solvents like dimethyl sulphoxide, benzyl alcohol, 1,3-dimethyl imidazolidone and $\mathrm{N}$-methyl pyrrolidone as diluent. Water was not selected as telmisartan was insoluble in it. Percentage recoveries of pyridine and dimethyl formamide were found to be good amongst these diluents. Whereas, in case of triethylamine, it was found to be more selective with respect to the diluent used. Recovery of triethylamine was achieved completely, only when $\mathrm{N}$-methyl pyrrolidone was used as diluent (Table 1). Sample size also played an important role for recovery of triethylamine (Table 2). Based on the experimental results, sample size for triethylamine was fixed as $50 \mathrm{mg}$. In case of pyridine and dimethyl formamide, their response in flame ionization detector (FID) was poor. Therefore the sample size was fixed as $500 \mathrm{mg}$. A typical chromatogram of standard showing elution pattern of triethylamine, pyridine and dimethyl formamide is shown in fig. 2.

System precision was carried out by analyzing freshly prepared standard solution for six times as per the method. Method precision study was carried out by preparing the sample in replicate after spiking with triethylamine, pyridine and dimethyl formamide with respect to their specification limit. Linearity was checked by preparing five different concentrations of triethylamine $(0.32-4.8 \mu \mathrm{g} / \mathrm{ml})$, pyridine $(5.08-30.5$ $\mu \mathrm{g} / \mathrm{ml})$ and dimethyl formamide (22-131.9 $\mu \mathrm{g} / \mathrm{ml})$. Solutions were prepared in triplicate at each level and the results are tabulated in Table 3.

Solutions for limit of detection (LOD) and limit of quantification (LOQ) were prepared in replicate and analyzed. For LOQ, solutions containing $0.32 \mu \mathrm{g} / \mathrm{ml}$, $5.08 \mu \mathrm{g} / \mathrm{ml}$ and $22 \mu \mathrm{g} / \mathrm{ml}$ of triethylamine, pyridine and dimethyl formamide, respectively were used. For LOD, solutions containing $0.1 \mu \mathrm{g} / \mathrm{ml}, 1.7 \mu \mathrm{g} / \mathrm{ml}$ and $8 \mu \mathrm{g} /$ $\mathrm{ml}$ of triethylamine, pyridine and dimethyl formamide, respectively were used. Signal to noise ratio at limit of detection was above 3 for all three solvents and their precision at limit of quantification level was measured by calculating their percentage relative standard deviation (\% RSD). The \% RSD at LOQ of triethylamine, pyridine and dimethyl formamide was found to be $6.5,2.4$ and $3.0 \%$, respectively.

Accuracy of the method was tested by spiking the sample with triethylamine, pyridine and dimethyl formamide at 50,100 and $150 \%$ of their specification

\section{TABLE 1: RECOVERY USING VARIOUS SOLVENTS AS DILUENT}

\begin{tabular}{lccc}
\hline \multicolumn{1}{c}{ Diluent } & \multicolumn{3}{c}{ \% Recovery } \\
\cline { 2 - 4 } & Triethylamine & Pyridine & Dimethyl formamide \\
\hline N-Methyl pyrrolidone & 99 & 101 & 99 \\
Dimethyl imidazolidone & 83 & 104 & 105 \\
Benzyl alcohol & 7 & 100 & 98 \\
Dimethyl sulphoxide & 49 & 102 & 101 \\
\hline
\end{tabular}

Complete recovery of triethylamine was observed only when $\mathrm{N}$-methyl pyrrolidone was used as diluent. Recovery was found to be good for other residual solvents in all other diluents used.

TABLE 2: EFFECT OF SAMPLE SIZE ON RECOVERY USING N-METHYL PYRROLIDONE AS DILUENT

\begin{tabular}{cccc}
\hline Sample size & \multicolumn{3}{c}{ \% Recovery } \\
\cline { 2 - 4 } & Triethylamine & Pyridine & Dimethyl formamide \\
\hline $25 \mathrm{mg}$ & 99 & Not done & Not done \\
$50 \mathrm{mg}$ & 100 & Not done & Not done \\
$75 \mathrm{mg}$ & 91 & Not done & Not done \\
$100 \mathrm{mg}$ & 91 & 100 & 99 \\
$300 \mathrm{mg}$ & 82 & 103 & 98 \\
$500 \mathrm{mg}$ & 67 & 104 & \\
\hline
\end{tabular}

Recovery of triethylamine using $\mathrm{N}$-methyl pyrrolidone as diluent is specific with respect to sample size. Less recovery was observed with increase in sample size. 


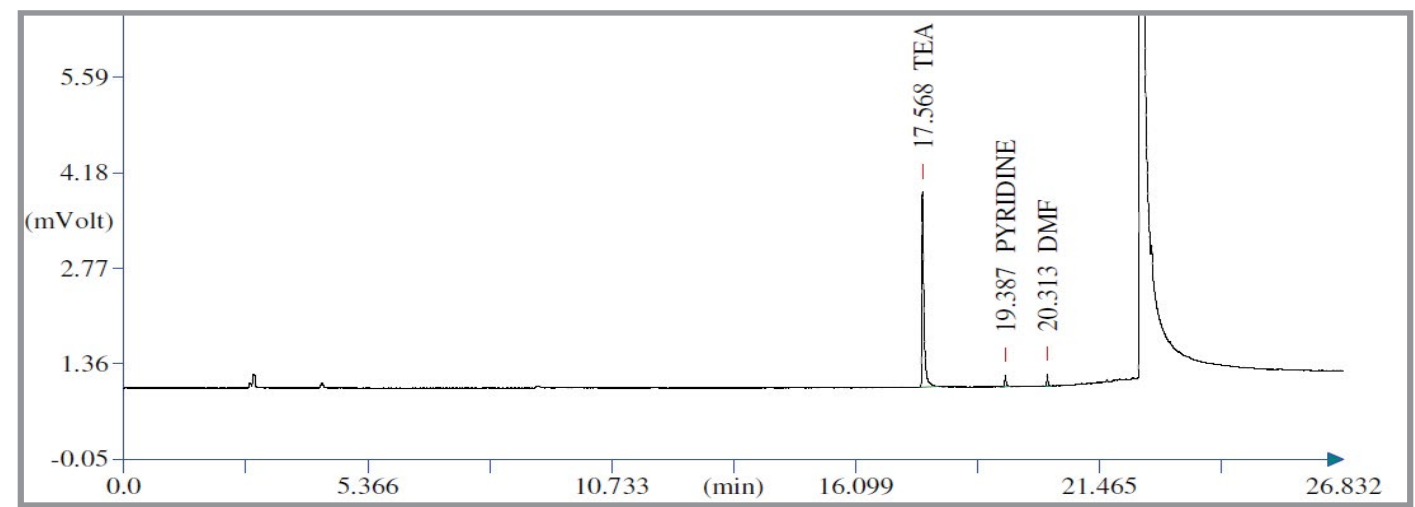

Fig. 2: Typical chromatogram of residual solvents.

Typical chromatogram showing retention times of triethylamine, pyridine and dimethyl formamide. The order of elution is triethylamine, pyridine followed by dimethyl formamide.

\section{TABLE 3: LINEARITY IN N-METHYL PYRROLIDONE DILUENT}

\begin{tabular}{lccc}
\hline Linearity parameters & Triethylamine & Pyridine & Dimethyl formamide \\
\hline Correlation $\left(\mathrm{r}^{2}\right)$ & 0.9998 & 0.9995 & 0.9997 \\
Slope & 3253 & 274.2 & 39.9 \\
Intercept & -188 & -17.2 & 83.2 \\
\%Y intercept w.r.t 100\% & -1.8 & -0.3 & 2.3 \\
\hline
\end{tabular}

Linear response for all residual solvents observed using $\mathrm{N}$-methyl pyrrolidone as diluent. The $\%$ intercept was found to be below $5 \%$ for all solvents.

limit. Solutions for recovery at each level were prepared in triplicate and analysed. Overall \% recoveries were found to be $97.1,99.6$ and $100.6 \%$ for triethylamine, pyridine and dimethyl formamide, respectively.

Analytical method for determination of triethylamine, pyridine and dimethyl formamide in telmisartan was developed on headspace gas chromatography using N-methyl pyrrolidone as a diluent. The method was found to be accurate, precise and specific. This headspace gas chromatographic method shall be used as routine analysis for determination of triethylamine, pyridine and dimethyl formamide in telmisartan and the same methodology shall be further extended for determination of amines in other products as well.

\section{Acknowledgements:}

The authors extend their appreciation to the Head, Pharmaceutical Research and Development, Piramal Enterprises Limited, Mr. Arno Enose for organizing the sample for study and supporting the project.

\section{Financial support and sponsorship:}

Nil.

\section{Conflicts of interest:}

There are no conflicts of interest.

\section{REFERENCES}

1. Kataoka H. Derivatization reactions for the determination of amines by gas chromatography and their applications in environmental analysis. J Chromatogr A 1996;731:19-34.

2. Kott L, Chen HM. Experimental considerations in headspace gas chromatography. Pharm Technol 2010;34:76-9.

3. Maris C, Laplanche A, Morvan J, Bloquel M. Static headspace analysis of aliphatic amines in aqueous samples. J Chromatogr A 1999;846:331-9.

4. Deshpande AR, Ramachandran G, Yamgar RS. Determination of diethylamine and triethylamine quantitatively using GCheadspace chromatography. Eurasian J Anal Chem 2012;7:43-8.

5. Raghuram P, Soma Raju IV, Sriramulu J. GC quantification of cyclopropylamine, diethylamine and triethylamine in active pharmaceutical ingredients. Chromatographia 2010;71:963.

6. Yan CT, Jen JF. Determination of aniline in water by microwave assisted headspace solid phase microextraction and gas chromatography. Chromatographia 2004;59:517-20.

7. Moore WM, Edwards RJ, Bavda LD. An improved capillary gas chromatography method for triethylamine Application to sarafloxacin hydrochloride and $\mathrm{GnRH}$ residual solvents testing. Anal Lett 1999;32:2603-12.

8. Hauel N, Dach R, Heitger H, Meyer O. Process for manufacture of telmisartan. U.S. Patent No. 7,193,089; 2007.

9. EDQM Europe. Content of the dossier for chemical purity and microbial quality.2007: PA/PH/CEP(04) 14R.

10. ICH guidelines. Impurities in New drug substances. 2007: Q3A(R2). 